\title{
Education Research: Neuroradiology curriculum in neurology residency training programs
}

\section{How we teach neuroimaging}

Paul D. Johnson, MD, Stefan Sillau, PhD, Joseph C. Masdeu, MD, PhD, Douglas E. Ney, MD, and Pearce J. Korb, MD

Neurology ${ }^{\circledR}$ 2019;92:199-203. doi:10.1212/WNL.0000000000006812

\section{Abstract}

\section{Objective}

To better understand how the essential skill of interpreting various neuroimaging studies is taught to neurology residents in Accreditation Council for Graduate Medical Education (ACGME)-accredited training programs.

\section{Methods}

A 22-question survey was sent electronically to 150 ACGME adult neurology program directors. We collected data regarding the presence of a neuroimaging curriculum, frequency of review sessions and testing, resource availability, and program director confidence in neuroimaging skills of graduating residents. We collected average scores on the neuroimaging section of the Resident In-service Training Examination of graduating residents for the past 3 years, which we attempted to correlate with resource availability.

\section{Results}

One-third of neurology residency programs do not have a neuroimaging curriculum, and half of training programs do not require a neuroimaging rotation. On average, trainees spend 1 hour per week reviewing imaging with radiologists. Program directors believed trainees receive insufficient neuroimaging training, with a median satisfaction rating on a Likert scale (0-100) of 35 (interquartile range 27-47). Few programs take advantage of online training resources.

\section{Conclusion}

Opportunities exist to improve neuroimaging education in neurology resident education. This can be done by closer adherence to the American Academy of Neurology neuroimaging curriculum guidelines, especially by expanding access to online resources and additional emphasis on imaging review with neurology subspecialists.
Correspondence

Dr. Johnson

johnson2089@gmail.com

From the University of Colorado (P.D.J., S.S., D.E.N., P.J.K.), Denver; and Weill Cornell Medicine (J.C.M.), New York, NY.

Go to Neurology.org/N for full disclosures. Funding information and disclosures deemed relevant by the authors, if any, are provided at the end of the article. 


\section{Glossary}

AAN = American Academy of Neurology; ACGME = Accreditation Council for Graduate Medical Education; IQR = interquartile range; RITE $=$ Resident In-service Training Exam.

Neurologists regularly utilize neuroimaging studies in the course of clinical care. The vast majority of these studies, over $98 \%$, are interpreted for reimbursement by radiologists. ${ }^{1}$ Despite this, the clinical neurologist frequently relies on his or her own interpretation of the images to guide clinical care. In an international survey, $79 \%$ of neurologists reported making clinical decisions on stroke care based solely on their own interpretation of neuroimaging studies. ${ }^{2}$ Fewer than $8 \%$ of neurologists rely entirely on someone else's interpretation of an imaging study to make clinical decisions, most often using a combination of their own and someone else's read. ${ }^{3}$ While neurologists benefit from the expert reading of images by trained neuroradiologists, they often have important clinical knowledge that influences the interpretation of the studies. It is critical that the practicing neurologist be familiar with the interpretation of neuroimaging studies, and understand the associated pitfalls, best practices, and risks.

In response to these needs, the American Academy of Neurology (AAN) published guidelines for neuroimaging curriculum for neurology trainees, with the goal of aiding neurology residents to achieve a level of diagnostic expertise in the interpretation of neuroimaging studies. ${ }^{4,5}$ The extent to which these guidelines have been adopted, what resources are available, and what didactic approaches are being used are unclear. ${ }^{6}$

The study goal was to understand the landscape of neuroimaging curricula in Accreditation Council for Graduate Medical Education (ACGME)-accredited programs, exploring opportunities to improve access to resources and adherence to the AAN curriculum guidelines. A secondary measure was to correlate various didactic approaches with results on the Resident In-service Training Exam (RITE), an annual assessment of neurology residents with over 50 neuroimaging questions.

\section{Methods}

A 22-question survey was sent electronically to 150 ACGME adult neurology program directors using the email address associated with their residency training program. Study data were collected and managed using Research Electronic Data Capture (REDCap) tools hosted at the University of Colorado, Denver. ${ }^{7}$ This project was reviewed and approved by the Colorado Multiple Institution Review Board.

Program directors were asked to provide average scores on the neuroimaging section of the RITE of graduating residents for the last 3 years. Response rates for RITE scores were low, with only 14 (32\%) providing scores for all 3 years.

\section{Data availability}

The full set of de-identified data is available upon request.

\section{Results}

We received 44 survey responses for a $29 \%$ response rate. All respondents were ACGME adult neurology residency program directors. The majority $(\mathrm{n}=39,89 \%)$ were from academic medical centers. Most programs $(n=29,66 \%)$ have a formal neuroradiology curriculum, but only half $(n=22)$ require that residents complete a neuroimaging rotation. Most (55\%) of these rotations were 4 weeks, but 3 (14\%) programs offered longer rotations. Aside from the annual RITE, only 9 (21\%) programs formally assess residents' ability to interpret neuroimaging studies.

MRI of the brain and CT angiography of the head and neck are the imaging modalities most frequently taught through formal didactics (figure 1). Nuclear medicine, carotid ultrasound, and transcranial Doppler studies are the least frequently taught imaging modalities.

Programs reported a variety of resources to support resident education of neuroimaging (figure 2). The most common were RITE review lectures and radiologic-pathology correlation conferences $(n=39,91 \%$ each). Most programs never provide formal lectures on MRI or CT physics $(n=23,54 \%)$. Only $10(23 \%)$ programs maintain a file of neuroimaging teachings cases, and only 7 of those programs had more than 100 cases of both CT and MRI.

Residents spend a median of 1 hour per week (interquartile range [IQR] 1-1) reviewing images face-to-face with neuroradiologists. Seven programs (16\%) have no regularly scheduled time to review imaging with neuroradiologists, while 11 programs (25\%) reported greater than 1 hour per week of face-to-face time with radiologists.

Program directors believed that graduating residents were competent with interpretation of brain MRI and CT angiogram of the head and neck, but were less confident about trainees' ability to interpret spine MRI or conventional catheter angiography (figure 3).

Program directors $(n=18)$ believed that trainees receive insufficient neuroimaging training, with a median satisfaction rating on a Likert scale (0-100) of 35 (IQR 27-47). Of the 31 responses, only $2(6.5 \%)$ indicated there was too much neuroimaging training and $4(13 \%)$ believed the amount of neuroimaging education was just right. Residents whose program 
Figure 1 Frequency of formal training in interpreting imaging studies of various modalities in Accreditation Council for Graduate Medical Education (ACGME)-accredited neurology residency training programs

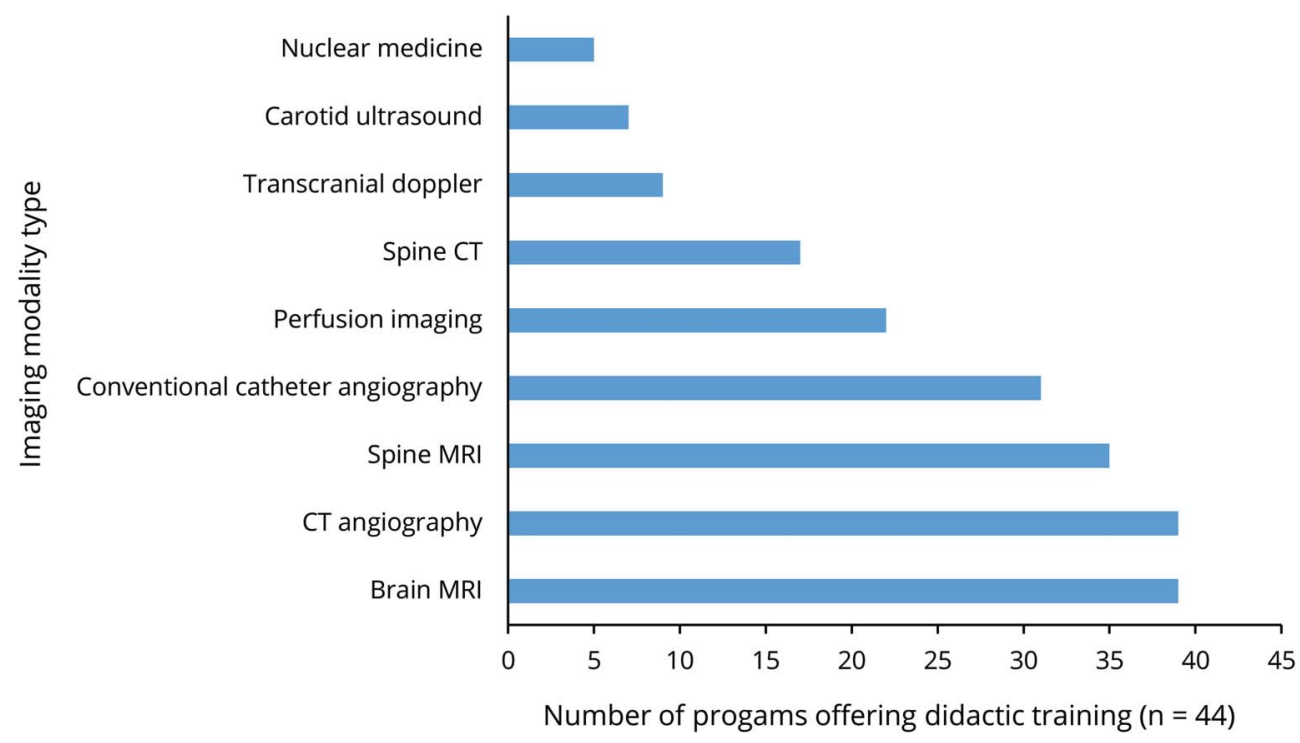

directors thought too much time was spent on neuroimaging education had lower neuroimaging RITE scores, losing 0.30 points for each incremental increase in program directors' satisfaction with the amount of neuroimaging education $(95 \%$ confidence interval $0.14-0.45, p=0.0009$ ).

RITE scores for the 2014-2016 graduating classes fell within a narrow range, with an interquartile variance between $5 \%$ and $7 \%$ for all years. There were no positive associations with having a neuroimaging curriculum, number of neuroimaging lectures, availability of neuroimaging educational resources, or the number of hours spent reviewing images each week and RITE scores.

\section{Discussion}

Accurate interpretation of neuroimaging studies is an essential skill for the neurologist, but formal training is inconsistent across ACGME-accredited neurology programs. Program directors overwhelmingly believed that additional training in

Figure 2 Frequency of educational resources available to trainees

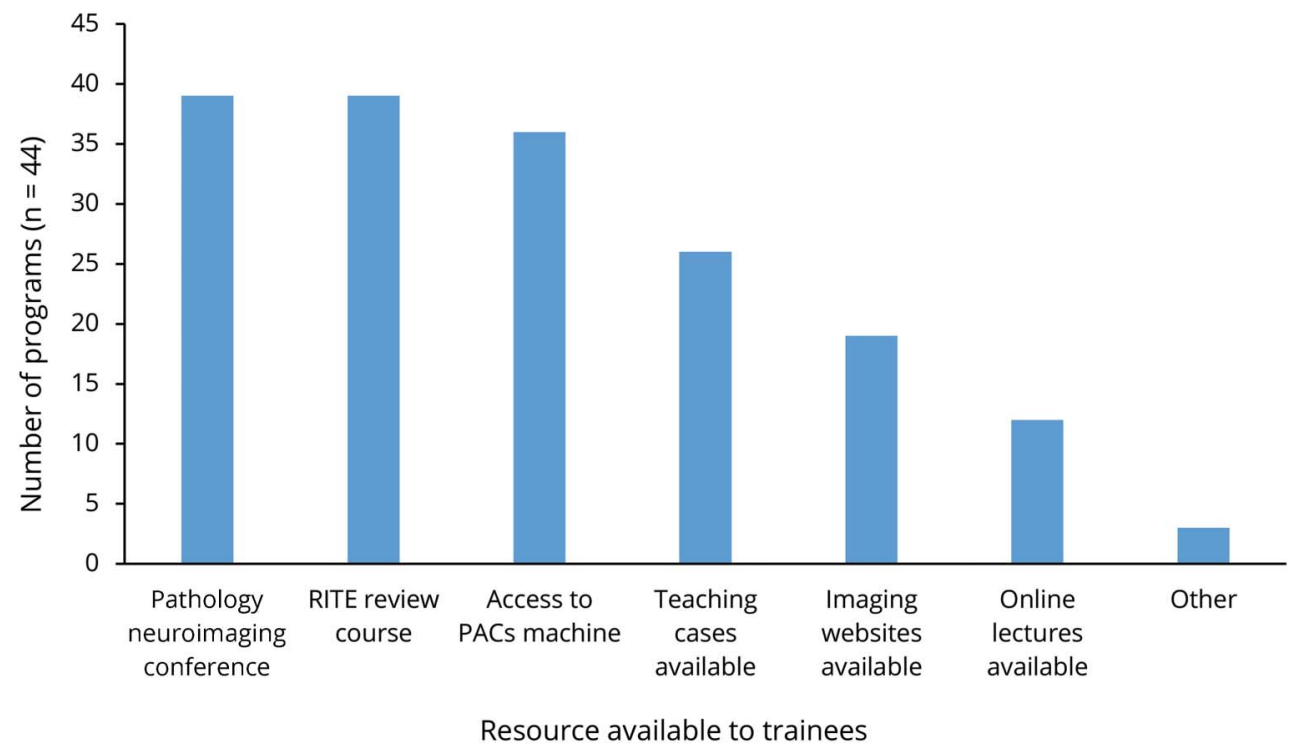

PACS = picture archiving and communication system; RITE = Resident In-service Training Exam. 
Figure 3 Program director satisfaction with graduating residents' ability to interpret imaging studies from various modalities

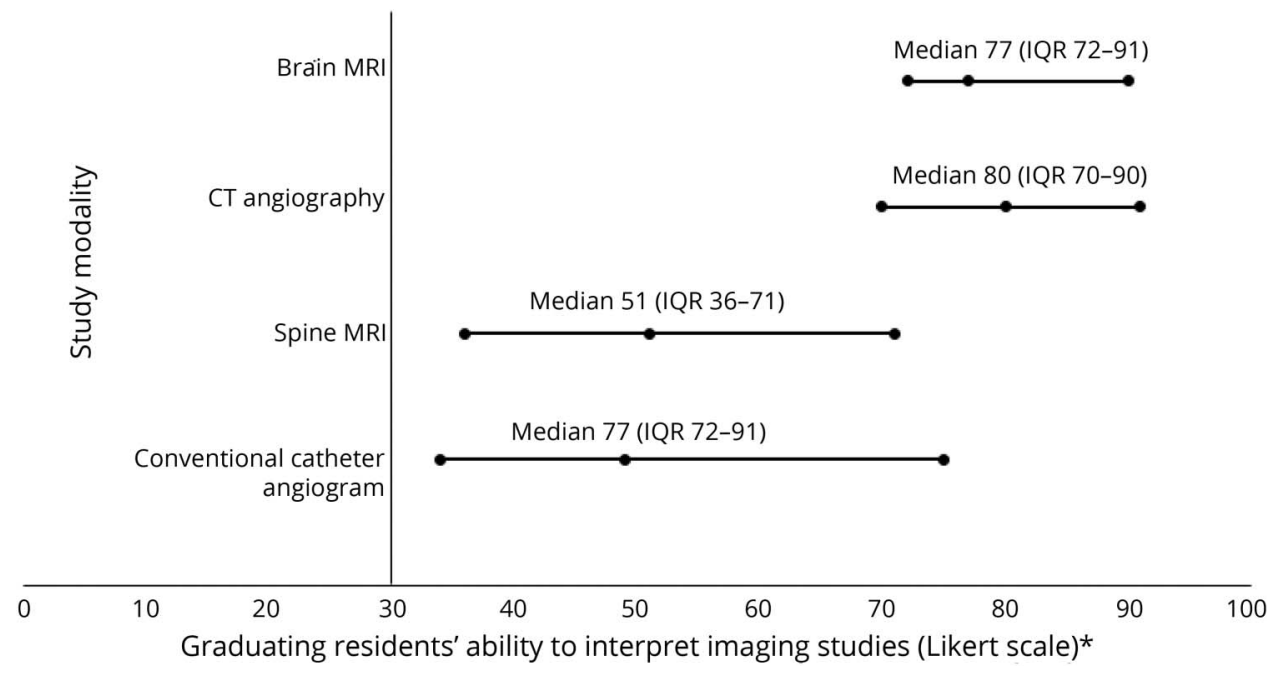

*Ranging from no confidence $(0)$ to complete confidence (100). IQR = interquartile range. neuroimaging would be beneficial, while those who did not tended to have residents with lower neuroimaging RITE scores. Program directors believed residents could improve their interpretation of catheter angiograms and spine MRI, but could competently interpret brain MRI and CT angiography, modalities that are critical in point-of-care evaluation in many settings.

This survey and others demonstrate the infrequent use of ancillary resources such as websites, online lectures, and teaching cases in resident education. ${ }^{5,6}$ Additional electronic or web-based resources could supplement resident education in areas of perceived weakness. For example, recorded lectures could be made available to address spine MRI, catheter angiography, perfusion imaging, and carotid or transcranial Doppler ultrasound. Web-based teaching cases, such as those currently available through MedPix, would increase trainee exposure to common and uncommon imaging findings across modalities. ${ }^{8}$ The development of electronic resources could have wide appeal, be easily shared between programs, and standardize the educational experience.

Neuroradiologists are experts at interpreting neuroimaging studies and are natural educators for neurology residents, but are underutilized in many programs. Most residents spend an hour a week or less with radiologists. Increased face-to-face time to review and discuss studies may enhance resident education. This could be implemented through scheduled neuroimaging conferences or integrated into clinical care.

Although not addressed by our questionnaire, another source of neuroimaging teaching may be neurology faculty versed in neuroimaging. Typically, they will be experts in one area of neuroimaging, such as stroke, multiple sclerosis, or neuro-oncology. By reviewing imaging studies with residents during patient care, they integrate neuroimaging into the clinical process. This powerful learning exercise is likely a major contributor to the neuroimaging expertise residents acquire. By making notes in the electronic medical record on their reading of MRI and CT, just as they do for neurologic examinations, neurology residents can easily document this training.

The primary limitation of this study was the $29 \%$ response rate and even lower response for RITE scores, limiting our ability to characterize the national state of neuroimaging training and ability to correlate curricular measures with RITE achievement. We could not correlate increased resources, having a neuroimaging curriculum, or rotation length with RITE performance. Finally, while many programs reported limited teaching of transcranial Doppler, carotid ultrasound, and perfusion imaging, this may reflect the perceived importance of these studies in clinical practice.

Multiple opportunities exist to improve neurology residents' skill and comfort with interpreting neuroimaging studies, and ongoing efforts within training programs and through collaboration with the ACGME and professional groups such as the AAN should continue to be developed. The complexity and importance of neuroimaging in clinical practice is accelerating, and training programs must be proactive to maintain training standards.

\section{Author contributions}

P.D. Johnson: drafting/revising the manuscript, data acquisition, study concept or design, analysis or interpretation of data, accepts responsibility for conduct of research and final approval, acquisition of data, statistical analysis, study supervision. S. Sillau: analysis or interpretation of data, accepts 
responsibility for conduct of research and final approval, statistical analysis. J.C. Masdeu: drafting/revising the manuscript, analysis or interpretation of data, accepts responsibility for conduct of research and final approval. D.E. Ney: drafting/ revising the manuscript, data acquisition, study concept or design, analysis or interpretation of data, accepts responsibility for conduct of research and final approval, acquisition of data, study supervision. P.J. Korb: drafting/revising the manuscript, study concept or design, analysis or interpretation of data, accepts responsibility for conduct of research and final approval.

\section{Study funding}

No targeted funding reported.

\section{Disclosure}

P.D. Johnson, S. Sillau, and J.C. Masdeu report no disclosures relevant to the manuscript. D.E. Ney is the program director of an ACGME neurology residency program and reports no disclosures. P.J. Korb reports no disclosures relevant to the manuscript. Go to Neurology.org/N for full disclosures.

\section{References}

1. Babiarz LS, Yousem DM, Parker L, Rao VM, Levin DC. Volume of neuroradiology studies read by neurologists: implications for fellowship training. J Am Coll Radiol 2011;8:477-482.

2. Mechtler L, Fritz J. Viewpoints: Why neuroimaging plays a critical role in shaping the future of neurology. Pract Neurol 2016:16-19.

3. Masdeu JC. What do neurologists think about their role in neuroimaging training and practice? J Neuroimaging 1999;9:39-42.

4. Bakshi R, Alexandrov AV, Gomez CR, Masdeu JC. Neuroimaging curriculum for neurology trainees: report from the Neuroimaging Section of the AAN. J Neuroimaging 2003;13:215-217.

5. Masdeu J. Neuroimaging curriculum for neurology residents and fellows [November 2017]. Available at: aan.com/siteassets/home-page/tools-and-resources/academicneurologist-researchers/program-director-tools/00neuroimagingtrainingguidelines_ tr.pdf. Accessed March 1, 2018.

6. Adair JC, Rudnicki SA, Boudreau E, Weiner WJ, Coyle PK, Corboy JR. Survey of training programs' means for promoting neurology and attracting trainees. Neurology 2006;67:936-939.

7. Harris PA, Taylor R, Thielke R, Payne J, Gonzalez N, Conde JG. Research electronic data capture (REDCap): a metadata-driven methodology and workflow process for providing translational research informatics support. J Biomed Inform 2009;42:377-381.

8. US National Library of Medicine. MedPix [Website]; 2016. Available at: medpix.nlm. nih.gov/home. Accessed March 13, 2018.

\section{The AAN Has Your Back!}

Every day, the AAN is fighting for you. From actively lobbying members of Congress for common sense legislation, to meeting with regulators to demonstrate the value of neurology and reduce regulatory hassles, the Academy is forcefully countering any threats to your profession and patient access to care. Learn more at AAN.com/policy-and-guidelines/advocacy, read the bimonthly Capitol Hill Report and monthly AANnews member magazine, and respond to Advocacy Action Alert emails when we invite you to share your voice with Congress.

Get into the conversation at \#AANAdvocacy.

\section{Visit the Neurology ${ }^{\circledR}$ Website at Neurology.org/N}

- More article-based content on home pages

- $\quad$ Streamlined menus and navigation

- Enhanced blog sections for specialty areas

- Same experience on desktop, tablet, and mobile devices

- Audio summaries of current issues

- Improved article reading experience; links more evident (pdf, analytics, social media)

- Neurology ${ }^{\circledR}$ Clinical Practice initiative "Practice Current" global surveys will be accessible across sites

f Find Neurology ${ }^{\circledR}$ on Facebook: http://tinyurl.com/neurologyfan

Follow Neurology ${ }^{\circledR}$ on Twitter: https://twitter.com/GreenJournal 


\section{Neurology}

\section{Education Research: Neuroradiology curriculum in neurology residency training programs: How we teach neuroimaging}

Paul D. Johnson, Stefan Sillau, Joseph C. Masdeu, et al. Neurology 2019;92;199-203

DOI 10.1212/WNL.0000000000006812

\section{This information is current as of January 21, 2019}

\section{Updated Information \&} Services

References

Subspecialty Collections

Permissions \& Licensing

Reprints including high resolution figures, can be found at: http://n.neurology.org/content/92/4/199.full

This article cites 5 articles, 1 of which you can access for free at: http://n.neurology.org/content/92/4/199.full\#ref-list-1

This article, along with others on similar topics, appears in the following collection(s):

All Education

http://n.neurology.org/cgi/collection/all_education

Computer use in education

http://n.neurology.org/cgi/collection/computer_use_in_education Methods of education

http://n.neurology.org/cgi/collection/methods_of_education

Information about reproducing this article in parts (figures,tables) or in its entirety can be found online at:

http://www.neurology.org/about/about_the_journal\#permissions

Information about ordering reprints can be found online:

http://n.neurology.org/subscribers/advertise

Neurology ${ }^{\circledR}$ is the official journal of the American Academy of Neurology. Published continuously since 1951, it is now a weekly with 48 issues per year. Copyright () 2019 American Academy of Neurology. All rights reserved. Print ISSN: 0028-3878. Online ISSN: 1526-632X.

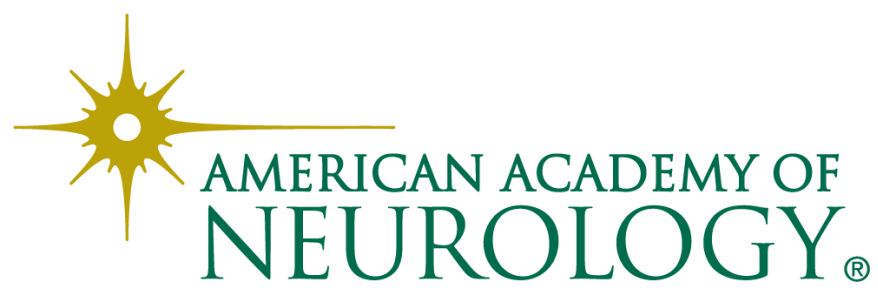

